\title{
Self-orientalization and Its Counteraction against the Cultural Purpose of Gu Hongming in His Discourses and Sayings of Confucius
}

\author{
Mingguo Zhong \\ Chongqing Jiaotong University, China \\ Email: bananabb@126.com
}

\begin{abstract}
Gu Hongming endowed his Discourses and Sayings of Confucius, the translation of Confucius' Lun $Y u$, with a mission of improving the image of Chinese culture. In order to achieve the purpose, the translator summoned a strategy of extreme domestication, fully catering to English language grids and Western value system. However, it is just the adaptation of such a strategy that makes the translation strongly self-orientalized, which clears up the intended purpose of the translation, depriving it of the power of achieving its intended cultural mission.
\end{abstract}

Index Terms - cultural identity, extreme domestication, self-orientalization, cultural mission

\section{INTRODUCTION}

The translation of Confucius' Lun Yu, one of the essential classic works of Chinese ancient philosophy and culture, has been the focus of translation studies since $19^{\text {th }}$ century. Until today, there are over 50 versions of different languages published, the most well-known of which, Gu Hongming's version, has been arousing many arguments. His version was published by Killy and Walsh Limited in 1898 when China, economically and politically marginalized, lost confidence in cultural communication. Dominated politically, economically and culturally by the West, Chinese culture lost the power of self-presentation and unfortunately became an object controlled by the West culture. In the presentation of West culture, Chinese culture is an unprogressive and childish culture at a standstill (Hegel, 2001), while Chinese nation is an immoral and degenerated one, without any redeeming quality (Zhou, 1999). Obviously, Gu Hongming, highly provoked by the negation and contempt from the West, started his translation of Discourses and Sayings of Confucius (regarded as the representative work of Chinese culture) and struggled to recreate image of China deliberately belittled in Western discourse hegemony. That is, Gu Hongming expected that his translation was to create image of China and make westerners realize the true value of Chinese culture so as to alter their negative attitude to China. Gu adopted a strategy to achieve his cultural expectation, but whether the strategy successfully achieved his expectation would be doubted. By the analysis of Gu's translation strategy and its objective effect, this paper will reveal the fundamental contradiction between self-orientalization in Gu's version and his cultural expectation and translation strategy, which finally clears up his intended purpose of the translation.

\section{Contradiction between the Purpose and the Means of Self-orientalization}

Since the West started and established the industrial culture of strong economic power, it has constructed a world order around the core of Western value system and imposed the order on other regions of the world economically, politically and culturally. In the order, the West turned to be the dominator and producer of discourse in creating cultural image while controlling the power of discourse in non-west regions so that it dominates the process of discourse production to establish a discourse system around binary opposition between the West and the East. In the system, the West is the world centre of civilization, freedom and forwardness while the East is "the marginalized part of inferior quality, weird, unchanged and passive" (Zhou, 2004, p11), and the synonym of barbarism, backwardness and autocracy. Hence, enforced to accept the political, economic and cultural order dominated by the West, the non-western economically-marginalized regions have to express themselves with a reference to the value system of the West. In a word, the development of modern culture in the East is characterized by the mental and identity domination of the West.

The West domination in cultural development of the East has been one of the researches of Orientalism started in the later half of $20^{\text {th }}$ century. Dirlik in his Post-revolution Atmosphere mentioned the concept of self-orientalization many times and stated that self-orientalization is a "conspiracy" established by European orientalists and Asian intellectuals together (Dirlik, 1999, p279). The conspiracy here is actually self-orientalism in the East. Zhou Ning has had a systematic generalization and conclusion of self-orientalization in the following three aspects. First, self-orientalization means that the East is enforced to confess the world order of West centralism and the binary opposition between the West and the East, that is, forwardness and backwardness, freedom and autocracy, civilization and barbarism. It further identifies superiority of the West and inferiority of the East and surrenders to the cultural hegemony of the West. 
Second, self-orientalization is a process of self-criticism and cultural reformation. That is deorientalization , which contains two extremes: one is to completely decry eastern tradition and turn to be thoroughly westernized, and the other is to promote eastern tradition in the world order dominated by the West. It is noticeable that both the two extremes contain both agreement with and resistance to the West. Third, deorientalization establishes not only a relationship between the East and the West, but also a relationship among eastern countries. The process of deorientalization also contains mutual-orientalization within the East itself, that is, which country is more oriental or which country is more western. On the basis of that, self-realization of countries of the East is formed (Zhou, 2006). It is concluded from the above statements that, in the world order dominated by the West, the East actually makes a self-presentation in a discourse system established by the West with the reference to the West. This proves that both "complete westernization" or "promotion of eastern tradition in the west world" cannot help the eastern countries establish their self-presentation and self-identity.

The two extremes of self-negation and cultural reformation mentioned above also show the two major modes of how Eastern countries create and develop cultural identity in the discourse system dominated by the West: deorientalization and promotion of the eastern tradition. The former is to decry their own culture and tradition in order to integrate the East into the West while the latter is to promote their own value in the world order controlled by the West to fight against the judgment and denial from the West in order to construct their own cultural identity. The two modes which seem contradictory are actually the means to reconstruct self-identity in the cultural system of binary opposition of the West and the East.

However, the two means of constructing cultural identity, characterized by self-orienalization, are contradictory to each other. That is the contradiction between the means and the purpose. Deorientalization cannot construct unique self-identity with the integration of the East into the West but become an extensive part of the West with a loss of eastern tradition. Promotion of the eastern tradition is seeking for the advancement of the East over the West or the similarities between the East and the West, depriving the power of promoting the uniqueness of eastern culture, so it also cannot establish a true self-identity. Therefore, the contradiction here will inevitably result in the failure of self-identity construction of the East.

\section{Gu's Translation Strategy in His Discourses and SAyings of Confucius and Its EfFects}

The scholars of German skopos theorie like Hans Vermeer believe that translation as an act contains certain purpose (Vermeer, 2000; Nord, 1997/2001), so a translator's act of translation including the formulation of translation strategy must be controlled by his or her purpose. Hence, a research on translation strategy with an analysis of the effects of a version will help us acquire the translator's cultural purpose and assess whether the translation has achieved his purpose.

This paper will first analyze the linguistic strategies adopted in Gu's version. Here linguistic strategies refer to the translator's means of processing linguistic features and text styles of the source text. The translator will decide whether the version maintains linguistic features and styles of the source text or keeps close to the linguistic grids of the target language. Linguistic features of a text include many aspects like sentence pattern, person, mood as well as cohesion and coherence (Lian, 1993); style of a text includes words, sentence pattern, context and coherence etc. (Leech \& Short, 2001). Limited by the content, the paper cannot have a comprehensive research on the whole version but it will take the seventh section of Chapter 3 and the first section of Chapter 19 for example to make a contrastive study on sentence pattern between the source and the target since sentence pattern is an aspect of both linguistic features and text style.

Eg1:子曰: “君子无所争。必也射乎！揖让而升, 下而饮。其争也君子。”(Lun Yu: Chapter 7 of Part III)

Gu's Version: Confucius remarked, “A gentleman never competes in anything he does, ---except in archery. But even then, when he wins he courteously makes his bow before he advances to make his place among the winners; and, when he has lost he walks down and drinks his cup of forfeit. Thus, even in this case of competition, he shows himself to be a gentleman.”(Gu, 1898, p.16)

Eg 2: 棘子成曰: 君子质而已矣, 何以文为? 子贡曰: 惜乎, 夫子之说君子也, 驱不及舌。文犹质也, 质犹文 也, 虎豹之蝣, 犹犬羊之鞹。(Lun Yu: Chapter 8 of Part XII)

Gu's Version: An officer of a certain state on one occasion remarked to a disciple of Confucius, saying: "A wise and good man wants only the substance; why should he trouble about the style?"

"I am sorry to hear you make such a statement," replied Confucius' disciple, "What you would say is true; but, stated in that way, it is impossible for men not to misunderstand your meaning. To be sure, the style comes out of the substance, but the substance also comes out of the style. For the substance of a tiger or a leopard is the same as the substance is the same as the substance in the skin of a dog or a sheep."(Gu, 1898, p.99)

Eg3: “子张曰: 士见危致命，见得思义，祭思敬，丧思哀，其可已矣。”(Lun Yu: Chapter 1 of Part XVIV)

Gu's Version: A disciple of Confucius remarked, “A gentleman in presence of danger should be ready to give up his life; in view of personal advantage, he should think of what is right; in worship, he should be devout and serious; in mourning, he should show heartfelt grief: the above is about the sum of the duties of a gentleman.”(Gu, 1898, p.169)

Example 1 contains 4 single sentences among which the first three share the same subject “君子”, while its English version is consist of three single sentences. That is, the first two single Chinese sentences are transferred to an English 
single sentence with an adverbial prepositional structure. The third Chinese sentence containing two juxtaposed V-V structure is translated into two juxtaposed compounding sentences and the fourth sentence of a subject-adjective structure into a juxtaposed single sentence with a time phrase in English. Meanwhile, Gu used the pronoun he (his, himself) 11 times so the frequent employment of pronouns makes his version more close to a standardized English sentence. In addition, two rituals mentioned in the source text, “揖让而升” and “下而饮”, are not faithfully maintained in the version; the former is partly translated and the latter is mistranslated into "drinking a cup of alcohol if failed". The same strategy can be apparently found in the translation of Example 3.

In Example 2, “质” in the source text refers to a good nature or quality; “文” refers to "external talents (rituals or manners)", which means a person's outer manifestation; and “鞹” means furred animal skin. The three words are respectively translated into "substance", "style" and "skin". However, "substance" in English is not equal to "personal quality", and "style" related to a person is generally not used to mean "external talents" while "skin" doesn't contain the meaning of "furred". It can see that Gu's version simplified the meaning of the three words of the source text which seems unclearly expressed.

The above contrastive analysis proves that Gu Hongming's Discourses and Sayings of Confucius is consist of many compounding sentences of subordinate constructions with typical hypotactic features. A frequent employment of pronouns and connective words makes the version cohesive. Most of the words in the version are common and popular to make the version fluent and easy-reading. Conclusively, the strategy makes the version a standardized English text.

Secondly, the paper will study the cultural strategy employed in translation. Here, a cultural strategy means how a translator treats cultural elements in translation, e.g. concepts, tradition and customs or ways of acts which appear in source text to represent source culture.

The cultural strategies in Gu's Discourses and Sayings of Confucius are reflected by four acts. One is to get rid of proper nouns in the source text to reduce English readers' unfamiliarity with them(Gu, 1898, preface, p.Vii-Viii). The most typical example is that Confucius' disciples' names are not translated except Zilu's and Yanhui's and other people's names are omitted or noted with very few maintained. In addition, only a few place-names are transliterated and most also omitted. Specifically, when some important people are mentioned, a correspondence to similar figures in western culture will be introduced. For example, the note for Yan Hui is "the St. John of the Confucius gospel, ---a pure, heroic, ideal character, the disciple whom the Master loved" and Zilu is compared to "the St. Peter of the Confucian gospel; a brave, latrepid, impetuous, chivalrous character" while the note for Wu Wang (Emperor Wu) is "the warrior king or the conqueror: the Solomon of Chinese history". The second one is that Gu had a tendency to compare cultural phenomenon and historical stages in the source text to so-called "similar" phenomenon and stages in western culture so as to display the similarities between the West and the East. For example, the note for “齐国” and “鲁国” is “the France of the Chinese history" and "the England of Chinese history", and the note for 诗经, "Now called the Canon of Poetry, one of the so-called five classics, is the Bible of China", directly compares a philosophical work of Confucianism to the Bible. Third, many opinions in the source text are noted with "similar" ones stated by Goethe, Voltaire, Tennyson or Horace etc., who are the famous scholars, poets, philosophers or politicians in the West. It shows that the translator is seeking for the similarities between the two. Fourth, a few typical Chinese cultural concepts are transferred to popular concepts of the West. An example is that “入太庙，每事问” is translated into “When he attended the service at the Great Cathedral (ancestral temple of the reigning prince), he always enquired what he would do at every stage of the service" (here the bold letters are noticed by the author). Here, “太庙” as a representative element of Chinese culture is translated into "the Great Cathedral”, “天命” into "the laws of God" and “圣人” into "holy men”. Therefore, Gu's cultural strategies are also an extreme domestication to Western cultural system.

\section{Gu’s SElf-Orientalization AND Its Clearing Up of His PuRPOSE}

A translator's cultural purpose in his translation will unavoidably be reflected by how he looks at the source culture and target culture. The purpose will exert effects on his translation strategies and be found in the final version. Here, how a translator looks at culture is actually a mirror of his cultural purpose.

As a talent in academics, education and politics of China throughout the end of Qing Dynasty and the beginning of Republic of China (1912-1949), Gu has been studied academically and culturally by Chinese scholars since his birth and also been researched by some western scholars. Although he was seriously criticized by Chen Duxiu, Cai Yuanpei or Hu Shi in that he was conservative in doing everything to maintain Chinese traditional culture, he is finally honored to be "a speaker of eastern culture" (Yan, 1996, preface, p.4). According to his biography and other materials, his thoughts about culture are categorized into two points. One is that he has a thorough and comprehensive study on both western and eastern culture, while the other is that he was hypercritical of the western culture and approving of Chinese traditional culture concentrating Confucianism with strong feudalism, that is, he had a self-admiration of Chinese culture. More specifically, by his comprehensive knowledge about the two cultures, Gu was willing to criticize the shallowness and arrogance of the western civilization on the stand of Chinese culture in order to safeguard Chinese culture threatened by the West, although he couldn't realize the bad side of Chinese culture, some feudal thoughts, and he "provided the society with the rubbish of Chinese civilization" (Yan, 1996, preface, p.6). Generally speaking, Gu's cultural purpose is to spread Chinese culture with his cultural activities. 
Gu's translation of The Discourses and Sayings of Confucius is a significant means to achieve his cultural purpose. In his preface, $\mathrm{Gu}$ clearly announced his intention to do the translation. He firstly put forward critical comments on Legge's version and stated that Legge, as an English scholar on Chinese culture, was poor in literature education, assessing competence and literary sensibility in his translation of The Discourses and Sayings of Confucius. He also pointed out that Legge's version "cannot display the wits and moralities of Chinese nation which sound weird for western readers" (Gu, 1898, preface p.VII). Gu emphasized that his version, no longer strange or weird, would be accepted by most common western readers so that "British people's prejudice against Chinese people would be removed" (Gu, 1898, preface, p.X). Undoubtedly, Gu's cultural purpose is running through his translation, which is to make Chinese civilization comprehensively understood by the West and to promote the international status of China as well as to recreate image of China.

However, his translation of The Discourses and Sayings of Confucius, as a means to achieve his cultural purpose, is actually a reflection of self-orientalization. Gu's translation strategy was intended to prove that Chinese culture is not inferior to western culture, that is, the thoughts, value system and thinking modes in the western cultural system can be found in Chinese culture. That means Chinese culture exists only in that it has the similar thoughts, value system and thinking modes of the western cultural system. In a word, the great similarity between Chinese culture and Western culture is why the former has the value to exist. So with various translation measures, Gu's translation is seeking for similarities between Chinese culture and Western culture to show the value of Chinese culture and achieve his intention of creating image of China.

Here, Gu's cultural strategy is actually a simple logic: the existence of Chinese culture is rooted in similarities between Chinese culture and Western culture. The logic is apparently wrong in that similarities between one culture and the referent culture cannot prove the culture has value unless the referent culture has value surpassing other cultures. There is a formula to demonstrate that logically wrong inference.

Major Premise: Western culture has superior value over other cultures.

Minor Premise: Chinese culture is apparently similar to Western culture.

Conclusion: Chinese culture has the value to exist.

That's to say, Gu's cultural strategy in his translation is to some extent an acknowledgement that Western culture is superior over Chinese culture, although he was not intended to admit that.

The logical defect mentioned above is actually the major one in Gu's The Discourses and Sayings of Confucius, that is, his intention to prove the existence value of eastern culture with an exploration to the similarities between eastern culture and western culture is an ignorance of the uniqueness of Chinese culture. Obviously, his strategy to certify the existence value of Chinese culture is totally toward a wrong direction in that the value is not rooted in the similarities but in the uniqueness neglected by Gu so that his version cannot achieve his cultural strategy. Generally, the purpose of translation is to transfer the uniqueness of source culture to target culture. If the strategy is unable to maintain uniqueness of source culture but tend to seek for the similarities between source culture and target culture, the true value of the source culture will be definitely lost and the cultural strategy will fall into void. In a word, Gu's strategy of self-orientalization in his translation is actually contradictory to his intention of transmitting Chinese culture. Dominated by western culture and value system, his translation has finally turned to be a "conspiracy" to control the power of discourse. What western readers read from Gu's translation is not the pith and unique value of Chinese Confucianism but the evidence that the value of western culture is superiorly popularized throughout the world.

\section{CONCLUSION: RELATIONSHIP BETWEEN CUlTURAL INTENTION AND TRANSLATION STRATEGy IN TRANSLATION OF} CLASSIC PIECES

With a growing interest in translation of Chinese classic pieces, more scholars have focused on translators' cultural intention, which actually refers to a translator's cultural stand in his translation practice. More specifically, cultural stand includes the two trends: one is to achieve cultural exchange of spreading Chinese culture to other countries and the other one is to construct "image of China" to satisfy the demand of the West with the reference to Chinese culture. The former is a true reflection of Chinese culture so that a translator with the stand will adopt a translation strategy to make his version close to the source culture. The latter is just an exploitation of Chinese culture so that a translator with the stand will take a strategy to make his version close target culture and value system (Li, 2007).

However, the analysis on Gu's The Discourses and Sayings of Confucius has found a great contradiction between his stand and his translation. His stand is to spread the true value of Chinese culture to the world but his version is actually seeking for the existence value of Chinese culture in the value system of the West. Therefore, a translator's cultural stand is an important factor considered but his strategy is a more significant factor to guide the cultural trend of his version, which will reflect whether the version can really transmit the source culture. In other words, a translator, with his cultural stand confirmed, must adopt a relevant strategy to achieve the stand or his stand will definitely fail by his wrong strategy.

\section{REFERENCES}

[1] Dirlik, Arif. (1999). Post-revolutionary Air. Wang Ning (trans.). Beijing: China Social Science Publishing House. 
[2] Gu Hongming (Trans.) (1898). The Discourse and Sayings of Confucius. Shanghai: Kelly and Walsh Limited.

[3] Hegel, G. W. F. (2001). The Philosophy of History. Wang Zaoshi (trans.). Shanghai: Shanghai Bookstore Publishing House.

[4] Lian Shuneng. (1993). Contrastive Studies between English and Chinese. Beijing: Higher Education Press.

[5] Leech, G and Short. (2001). The Style of Fiction. Beijing: Foreign Language Teaching and Research Press.

[6] Li, Tuwang. (2007). Cultural Orientation and Translation Strategies. Foreign languages and teaching Press, 7, 53.

[7] Nord, C. (1997). Translation as a Purposeful Activity: Functional Approaches Explained. Shanghai: Shanghai Foreign Language Teaching Press.

[8] Vemeer, Hans J. (2000). Skopos and Commission in Translational Action. In Laurence Venuti(eds.), The Translation Studies Reader. London: Routledge, 221.

[9] Yan, Guanghui. (1996). Biography of Gu Hongming. Haikou: Hainan Publishing House.

[10] Zhou, Ning. (1999). China in the Eyes of the West through 2000 Years. Beijing: Tuanjie Publishing House.

[11] Zhou, Ning. (2004). Legends of Khitan. Beijing: Xueyuan Publishing House.

[12] Zhou, Ning. (2006). Image of China in Asia or the East: New Topics and Perspectives. Humanities, 6, 7.

Mingguo Zhong was born in Sichuan, China in 1968. He received his PH.D. degree in translation studies from Nankai University, China in 2009.

$\mathrm{He}$ is currently an associate professor in the School of Foreign Languages, Chongqing Jiaotong University, Chongqing, China. His research interests include translation studies and translation of Chinese classics.

Dr. Zhong is a member of Chongqing Association of Translation. 